\title{
The effect of grass-endophyte associations on feeding of Canada geese (Branta canadensis)
}

\author{
C.G.L. PENNELL and M.P. ROLSTON \\ AgResearch, Lincoln Science Centre, P.O. Box 60, Lincoln \\ chris.pennell@agresearch.co.nz
}

\begin{abstract}
Canada geese (Branta canadensis) and other herbivorous birds (e.g. paradise ducks, pukeko) can be a significant problem for both pastoral farmers and recreational turf managers in a number of locations in New Zealand. Canada geese were offered seeds and herbage of selected ryegrass combinations of (Lolium perenne) and endophyte (Neotyphodium lolii) to examine the effects of endophyte and the associated alkaloids on feeding behaviour. Forty geese were captured annually during the moult in January and contained in fenced areas by wing clipping. In both choice and no-choice feeding trials, geese consumed up to four times more endophyte-free than endophyteinfected ryegrass herbage. In a seed feeding trial, the geese did not discriminate on first exposure between the endophyte-free seed and that containing endophyte. However on Day 2 there was an $80 \%$ rejection of the seed containing endophyte compared to the endophyte-free seed. A similar rejection of $80 \%$ was observed after a three month endophyte-free feeding period, suggesting the rejection was a long term learned response involving post-digestion feedback. Grass/endophyte associations may add to the armoury of bird control methodology as a tool to manage birds using habitat modification.
\end{abstract}

Keywords: alkaloids, Canada geese, endophyte, herbage, post-digestion seed

\section{Introduction}

Canada geese and other herbivorous birds, e.g. paradise shelducks (Tadorna variegate) and pukeko (Porphynio porphynio), can be a significant problem for pastoral farmers, recreational turf managers, and city councils in a number of locations in New Zealand. In North America, Canada geese populations have increased to pest proportions which have led to human/goose conflicts in agriculture, municipal parks, water storage facilities, golf courses, and airfields (Gauthier \& Bedard 1991). Problems created by geese include bird strikes in the aviation industry, fouling of recreational areas, faecal contamination of water storage lakes and damage to crops. A number of researchers have demonstrated the deleterious effects of grazing by geese on young grass shoots causing mortality of the growing points (Kahl \&
Samson 1984; Groot Bruinderink 1989) while fouling is also a problem with up to 50 droppings per $\mathrm{m}^{2}$ (Gauthier et al. 1988).

In New Zealand there are potential problems when people create an "oasis effect" that attracts birds. The creation of artificial lakes, growing a range of grain crops that extends the feeding season and planting of shelter belts that provide roosting sites are examples that allow large colonies to establish. Geese are becoming more adapted to human behaviour in urban and arable environments (Smith et al. 1999).

Localised geese can be difficult to control using conventional technology. Alarm calls, sprays, poisons, live trapping, shooting, and relocation have all been tried and offer only short term relief (Cooper $\&$ Keefe 1997). A recent summary of such techniques has been published by Smith et al. (1999).

Several studies on the feeding preferences of geese and other birds provide clues to future potential control strategies. Conover \& Messmer (1996a) using Zebra finches (Taeniopygia guttata) fed tall fescue (Festuca arundinacea) seed infected with the endophyte (E+) Neotyphodium coenophialum. After four months of seed feeding trials, the birds were able to discriminate between $\mathrm{E}+$ seed and endophyte-free seed, (E-) and eventually consumed more E-. Conover \& Messmer (1996b), when feeding Canada geese tall fescue herbage $\mathrm{E}+$ and $\mathrm{E}$ - for 15 months, found that in a choice situation, geese with a $\mathrm{E}+$ grazing history spent $86 \%$ of their time grazing the E-. They suggested the delay in developing an aversion to the infected fescue may be based more on "post-digestion feed back" rather than any bitter taste.

Two types of mechanisms are operating in feed aversion: "Post digestion feedback" (PDF) described by Conover \& Messmer (1996b) where illness altered long term food preference of virtually all vertebrates. PDF develops from eating something not associated initially with taste but causing a malaise over time. Conditioned taste aversion (CTA) is when an animal or bird rejects a food after a taste and they form an aversion to the taste of the food (Garcia, et al. 1974; Riley \& Tuck 1985; Nicolas \& Lee 1999). CTA is more immediate and is the basis of many repellents that also use colour, taste and smell to create aversion. Increasing problems of geese damage in New 
Zealand pasture and turf situations prompted an investigation into the effects of feeding Canada geese with ryegrass herbage and seed infected with the endophyte Neotyphodium lolii, with known levels of endophyte alkaloids. These alkaloids are secondary metabolites produced by the ryegrass/endophyte association and protect the plant from insect predation and overgrazing.

\section{Methods}

Canada geese were obtained in full moult from the wild in January 2000 and 2001. The geese were wing clipped and confined on E- pasture and supplemented with crushed barley for a period of three weeks as a settling down period.

\section{Trial 1: Herbage cafeteria (choice)}

In 2000, Nui perennial ryegrass herbage infected with either its endemic "wild-type" endophyte $(\mathrm{E}+)$, or endophyte-free (E-), was fed in randomised plots (15 $\mathrm{m}^{2}$ ) in situ to 20 naïve Canada geese (no previous known exposure to endophyte material). To establish intake, herbage was cut to ground level from $0.5 \mathrm{~m}^{2}$ quadrats in both the grazed plot areas and caged areas after each 10-day grazing period. Geese were kept in one gaggle and shifted to the next replicate when the herbage on offer got below $300 \mathrm{~kg} / \mathrm{ha}$ or became fouled.

\section{Trial 2: Herbage assigned (no choice)}

On a "no-choice" trial two gaggles of seven geese of equal live weight, were placed in $5 \mathrm{~m}^{2}$ cages which were shifted to a new plot each day. The geese had access to water at all times and were also offered crushed barley once a day. The groups were placed on either Nui ryegrass E+ or E-. Herbage dry matter was determined both pre and post grazing each day for seven days.

\section{Trial 3: Seed feeding}

In Year 1 four gaggles of five geese were confined in $15 \mathrm{~m}^{2}$ plots and fed $500 \mathrm{~g}$ of perennial ryegrass seed cv. Kingston. Two groups were offered E+ (alkaloid profile: $35 \mathrm{ppm}$ ergovaline, $12 \mathrm{ppm}$ lolitrem $\mathrm{B}$ and $38 \mathrm{ppm}$ peramine) and two E-. This treatment was repeated each day for five days. Consumption of seed was determined by weighing the remaining seed after a two hour feeding period. The geese were supplemented with $500 \mathrm{~g}$ of crushed barley and fresh water daily for the duration of all the seed feeding trials.
In Year 2, a seed feeding trial with four ryegrass/ endophyte associations with different alkaloid profiles was conducted to identify the endophyte alkaloid responsible for aversion (Table 1). The trial was run over three days with only one feeding of the test material per day. Intake was measured for each of the three feeding days, by weighing the seed left after a three hour feeding exposure each day. Geese were separated into four replicate groups of five for each feeding and fenced apart from each other with a visual barrier. Individual geese were identified with coloured leg bands, to record the date of exposure to E+ seed throughout this trial. Geese that had been exposed to endophytic feed were referred to as "learned", while non-exposed geese were referred as "naïve". Another group of geese were only fed nil endophyte diets to maintain their naïvety.

\section{Trial 4: Learned response seed feeding (choice)}

After completion of the three day seed feeding (Trial 3 ), the geese were removed and maintained on Eherbage for a period of three months. These geese were then offered seed of Greenstone long-rotation ryegrass E- or infected with endophyte (Greenstone "Endosafe") in a no-choice trial. Greenstone "Endosafe" contains the alkaloids peramine and ergovaline, but no lolitrem B which is known to cause ryegrass staggers (Table 1 ). Intake was measured over two one-day feedings to determine if they had retained a "learned" aversion to the Greenstone "Endosafe" seed. Visual stimulus to feed was applied by putting a group of five naïve geese within sight and feeding on nil endophyte seed next to the "learned" geese.

\section{Trial 5: Learned response (cafeteria)}

Twelve geese with different histories of endophyte seed feeding exposure and eight "naïve" geese were tagged according to their history. These geese were then grouped into four gaggles of five birds and offered a choice of four trays of Greenstone seed, two with $\mathrm{E}+$ and two with $\mathrm{E}-$ in each gaggle. A video to determine the time taken for each bird to start feeding, the total feeding time, and the selection of either E+ or E- seed was recorded for each individual 
goose. Numbers of geese for this work was limited to those caught during the moult in January and the history of E+ exposure.

\section{Results and discussion \\ Herbage feeding}

In the ryegrass choice trial (Trial 1) "naïve" geese consumed more E- than E+ herbage on offer $(41 \%$ and $10 \%$, respectively. $P<0.05)$. This effect was not immediate, with the grazing preference developing over the nine days grazing interval. In the no-choice ryegrass grazing trial (Trial 2) the geese consumed more E- herbage on offer, compared with E+ $(30 \%$ and $5 \%$, respectively. $P<0.06$ )

\section{Seed feeding trials}

In the initial perennial ryegrass (cv. Kingston) seed feeding (Trial 3) using E- (2\% endophyte infection) and $\mathrm{E}+(89 \%$ endophyte infection), "naïve" geese consumed $100 \%$ of E- seed compared to only $15 \%$ of the $\mathrm{E}+(P<0.05)$. Results from the second year show that E- and AR1 endophyte ryegrass cultivars had no effect on the consumption over three successive feedings, whereas the same cultivars with wild-type or Endosafe endophytes resulted in a significant rejection after the first feeding (Figure 1). Of the endophyte alkaloids measured, ergovaline appeared to be the alkaloid most commonly associated with rejection of the herbage seed (Table 1).

Since consumption at the first feeding was between $70 \%$ and $100 \%$ (Figure 1) it would seem unlikely that taste or smell aversion was influencing intake over this feeding period. In these trials, aversion developed after one feeding, suggesting that avoidance is likely to be induced by PDF which enabled these birds to subsequently recognise the $\mathrm{E}+$ material and avoid it. This latter response could be associated with CTA as birds were able to discriminate and make a choice.

\section{Learned response with seed feeding}

Data from the video recordings (Trial 5) of mixed groups of geese from shared previous exposure to endophyte showed that previous exposure can influence subsequent feeding response (Table 2). Learned geese were slower to start feeding and spent less time feeding, suggesting that the birds had developed through PDF a CTA described in Nicolaus \& Lee (1999).

\section{Long term memory}

"Learned" geese which had been exposed to E+ and had three months on endophyte-free material, when returned to treatments of $\mathrm{E}+$ material as described in Trial 4, rejected the E+ at the first feeding, consuming $95 \% \mathrm{E}$ - and only $7 \% \mathrm{E}+$ seed $(\mathrm{P}<0.01)$. This indicates

Figure 1 Daily consumption of ryegrass seed fed to geese as a \% on offer over 3 days of several ryegrass/ endophyte associations.

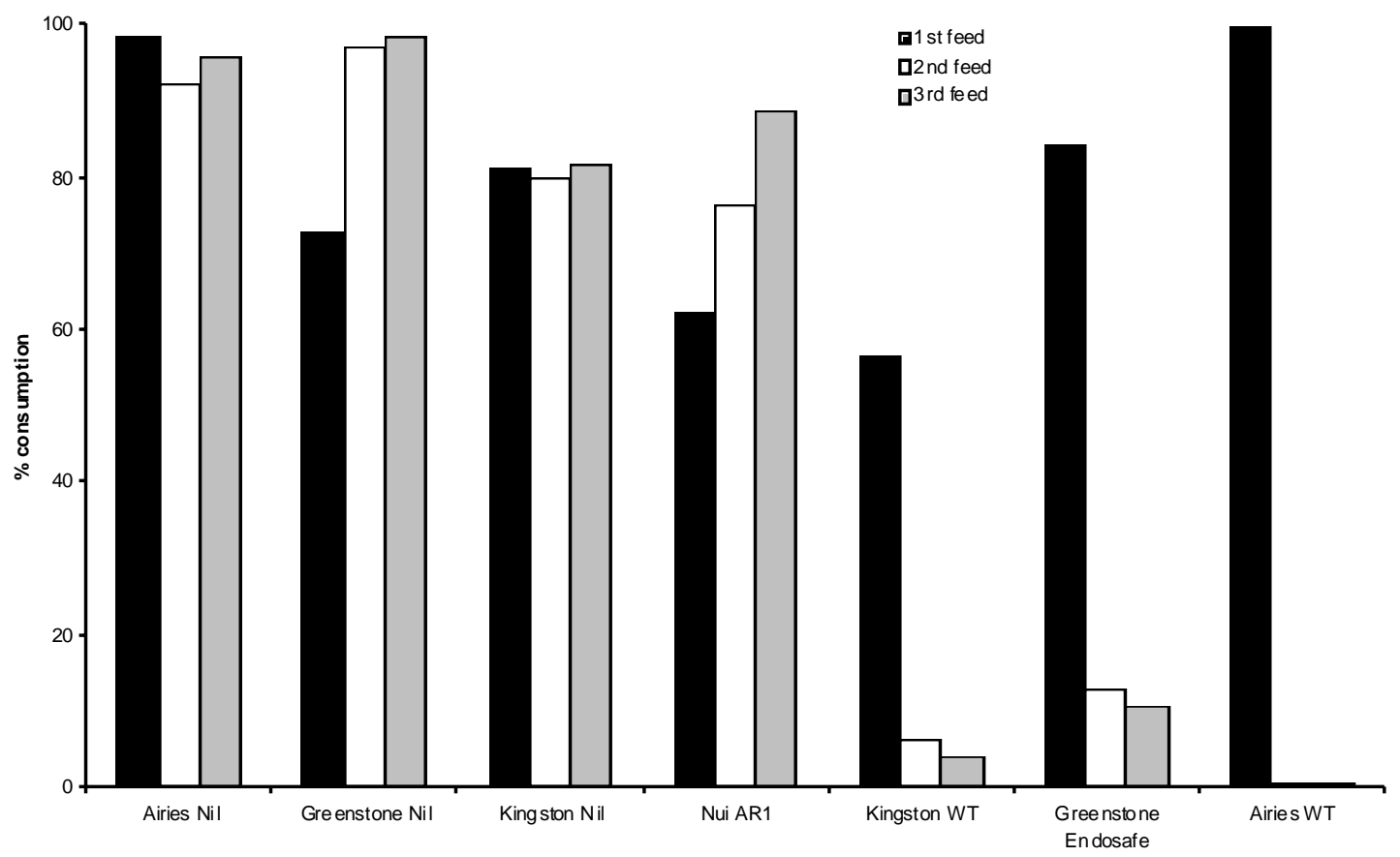


that long term memory exists for endophyte. The strong visual feeding stimulus recommended by P. Harper (pers. comm.), in the form of "naïve" geese feeding within sight of the learned groups, should have stimulated the learned geese to accept the food. PDF may be one mechanism which provokes the "learned" geese to recognise and reject the $\mathrm{E}+$ but it is possible that a form of CTA (Garcia et al. 1974; Riley \& Tuck 1985; Nicolaus \& Lee 1999) could influence how the geese recognised and so avoided the E+ material. Our work is in agreement with the results of Conover \& Messmer (1996b) but our work is the first to identify specific endophyte alkaloids involved in bird responses.

\section{Conclusion}

These results (summarised in Table 3) demonstrate that captive Canada geese showed marked learned response to the feeding of seed and herbage infected with selected endophytes. The Canada geese showed no aversion to the endophyte seed upon initial exposure, but learned on subsequent feeding to avoid material with ergovaline-producing endophytes.

Continued research into this area may offer potential as a natural living deterrent to birds by habitat modification.

There is potential for airport managers, city councils, water storage catchments and recreational managers to reduce herbivorous bird damage with appropriate habitat modification using selected grass/endophyte associations.

\section{ACKNOWLEDGEMENTS}

Garry J. Ottmann and Ross Millichamp (North Canterbury Fish and Game Council) and Kerry Sutton (Goose Guardians \& Ellesmere Promotions) for permission and assistance to capture geese and advice on geese management; AgResearch Celentis for funding the project.

\section{REFERENCES}

Conover, M.R.; Messmer, T.A. 1996a. Consequences for captive Zebra Finches of consuming tall fescue seeds infected with the endophyte fungus Acremonium coenophialum. Auk 113(2): 492-495.

Conover, M.R.; Messmer, T.A. 1996b. Feeding preferences and changes in mass of Canada geese grazing endophyte infected Tall Fescue. The Condor 98: 859-862.

Cooper, J. A.; Keefe, T. 1997. Urban Canada goose management: policies and procedures. Transactions of the North American Wildlife and Natural Resources Conference 62:412-430. Crop Protection 14: 257-259.

Garcia, J.; Hankins, W.G.; Rusiniak, K.W. 1974. Behavioural regulation of the milieu interne in man and rat. Science 185: 824-831.

Gauthier, G., J.; Bedard. 1991. Experimental tests of the palatability of forage plants in greater snow geese. Journal of Applied Ecology 28: 491-500.

Gauthier, G.; Bedard, Y; Bedard, J. 1988. Habitat use and activity budgets of greater snow geese in spring. Journal of Wildlife Management 52: 191-201.

Groot Bruinderink, G.W.T.A. 1989. The impact of wild geese visiting improved grasslands in the Netherlands. Journal of Applied Ecology 26 : 131-146.

Kahl, R.B.; Samson, F.B. 1984. Factors affecting yield of winter wheat grazed by geese. Wildlife Society Bulletin 12: 256-262.

Nicolaus, L. K.; Hanson Lee. 1999. Low acute exposure to organophosphate produces long-term changes in bird feeding behaviour. Ecological

Table 3 Summary of feeding responses (\% herbage or seed consumed) in the trials.

\begin{tabular}{llcc}
\hline $\begin{array}{l}\text { Trial number } \\
\text { History of geese }\end{array}$ & Endophyte plus & Nil endophyte \\
\hline Trial 1 Herbage naïve & Cafeteria (choice) & 10 & 41 \\
Trial 2 Herbage naïve & Assigned (No choice) & 5 & 30 \\
Trial 3 Seed naïve & Cafeteria (choice) & 15 & 100 \\
Trial 4 Seed learnt & Assigned (choice) & 7 & 95 \\
Trial 5 Seed (Long term memory) & Cafeteria (choice) & See Table 2 & See Table 2 \\
\hline
\end{tabular}


Society of America. Ecological Applications 9 (3): 1039-1049

Riley, A.L.; D.L. Tuck. 1985. Conditioned food aversions: a bibliography. pp. 381-437. In:

Experimental assessments and clinical applications

of conditioned food aversions. Eds. N.S. Braveman and P. Bronstein. New York Academy of Sciences, New York, USA.

Smith, A. E.; Craven, S. R; Curtis, P. D. 1999. Managing Canada geese in urban environments. Jack Berryman Institute Publication 16 and Cornell University Cooperative Extension, Ithaca, N.Y. 